\title{
Augmented expression of MYC and/or MYCN protein defines highly aggressive MYC-driven neuroblastoma: a Children's Oncology Group study
}

L L Wang ${ }^{1}$, R Teshiba ${ }^{1}$, N Ikegaki $^{2}$, XX Tang ${ }^{2}$, A Naranjo ${ }^{3}$, W B London ${ }^{4}$, M D Hogarty ${ }^{5}$, J M Gastier-Foster ${ }^{6}$, A T Look ${ }^{7}$, J R Park ${ }^{8}$, J M Maris ${ }^{5}$, S L Cohn ${ }^{9}$, R C Seeger ${ }^{10}$, S Asgharzadeh ${ }^{10}$ and H Shimada*,1

${ }^{1}$ Department of Pathology and Laboratory Medicine, Children's Hospital Los Angeles, University of Southern California Keck School of Medicine, Los Angeles, CA 90027, USA; ${ }^{2}$ Department of Anatomy and Cell Biology, College of Medicine, University of Illinois at Chicago, Chicago, IL 60612, USA; ${ }^{3}$ Department of Biostatistics, Children's Oncology Group Statistics and Data Center, University of Florida, Gainesville, FL 32607, USA; ${ }^{4}$ Division of Hematology/Oncology, Boston Children's Hospital and Dana-Farber Cancer Institute, Harvard Medical School, Boston, MA 02215, USA; ${ }^{5}$ Division of Oncology and Department of Pediatrics, Children's Hospital of Philadelphia, University of Pennsylvania School of Medicine, Philadelphia, PA 19104, USA; ${ }^{6}$ Department of Pathology and Laboratory Medicine, Nationwide Children's Hospital and Departments of Pathology and Pediatrics, Ohio State University College of Medicine, Columbus, OH 43210, USA; ${ }^{7}$ Department of Pediatric Oncology, Dana-Farber Cancer Institute, Harvard Medical School, Boston, MA 02215, USA; ${ }^{8}$ Department of Pediatrics, Seattle Children's Hospital, University of Washington School of Medicine and Fred Hutchinson Cancer Research Center, Seattle, WA 98105, USA; ${ }^{9}$ Department of Pediatrics, Division of Hematology/Oncology, University of Chicago, Chicago, IL 60637, USA and ${ }^{10}$ Division of Hematology/Oncology, Children's Hospital Los Angeles, University of Southern California Keck School of Medicine, Los Angeles, CA 90027, USA

Background: MYCN amplification with subsequent MYCN protein overexpression is a powerful indicator of poor prognosis of neuroblastoma patients. Little is known regarding the prognostic significance of the homologous MYC protein expression in neuroblastoma.

Methods: Immunostaining for MYCN and MYC protein was performed on 357 undifferentiated/poorly differentiated neuroblastomas. Results were analysed with other prognostic markers.

Results: Sixty-seven (19\%) tumours were $\mathrm{MYCN}(+), 38(11 \%)$ were $\mathrm{MYC}(+)$, and one $(0.3 \%)$ had both proteins $(+)$. $\mathrm{MYCN}(+)$ tumours and $\mathrm{MYC}(+)$ tumours were more likely diagnosed in children $>18$ months with stage4-disease. $\mathrm{MYCN}(+)$ tumours were associated with amplified MYCN, Unfavourable Histology (UH), and High-MKI (Mitosis-Karyorrhexis Index). MYC(+) tumours were also frequently UH but not associated with MYCN amplification, and more likely to have low-/intermediate-MKI. Favourable Histology patients without MYC/MYCN expressions exhibited the best survival ( $N=167,89.7 \pm 5.5 \%$ 3-year EFS, $97.0 \pm 3.2 \%$ 3-year OS), followed by UH patients without MYC/MYCN expressions ( $N=84,63.1 \pm 13.6 \% 3$-year EFS, 83.5 $\pm 9.4 \% 3$-year OS). MYCN $(+)$ patients and $\mathrm{MYC}(+)$ patients had similar and significantly low $(P<0.0001)$ survivals $(46.2 \pm 12.0 \% 3$-year EFS, $63.2 \pm 12.1 \%$ 3-year OS and $43.4 \pm 23.1 \%$ 3-year EFS, $63.5 \pm 19.2 \% 3$-year OS, respectively). Notably, the prognostic impact imparted by MYC expression was independent from other markers.

Conclusions: In this series, 30\% of neuroblastomas had augmented MYCN or MYC expression with dismal survivals. Prospective study of MYC/MYCN protein expression signature as a new biomarker for high-risk neuroblastomas should be conducted.

*Correspondence: Dr H Shimada; E-mail: hshimada@chla.usc.edu

Received 27 January 2015; revised 1 May 2015; accepted 6 May 2015; published online 2 June 2015

(c) 2015 Cancer Research UK. All rights reserved 0007-0920/15 
Peripheral neuroblastic tumours (pNTs, including neuroblastoma, ganglioneuroblastoma, and ganglioneuroma) are the most common extra-cranial tumours of childhood, accounting for $15 \%$ of childhood cancer mortality, and 650-700 cases are newly diagnosed each year in the United States. Patients with pNTs are classified into three risk groups (low, intermediate, and high) based on the combination of prognostic factors, including clinical stage, age at diagnosis, histopathology, MYCN proto-oncogene status, DNA index, and other chromosomal abnormalities (Brodeur et al, 1984, 1993; Shimada et al, 1999a,b; Weinstein et al, 2003; Maris et al, 2007; Cohn et al, 2009). Among these factors, MYCN amplification, which is detected in about $20 \%$ of all pNTs, is considered as the most reliable genomic hallmark of aggressive clinical behaviour (Brodeur et al, 1984; Seeger et al, 1985; Goto et al, 2001).

The vast majority of MYCN-amplified tumours are known to express elevated levels of MYCN protein. Morphologically, MYCN-amplified tumours are often characterised by the presence of one or a few prominent nucleoli (Kobayashi et al, 2005; Thorner et al, 2006; Suganuma et al, 2013) and associated with high mitotic and karyorrhectic activities (Goto et al, 2001). Recent studies suggest that MYCN protein expression rather than MYCN proto-oncogene amplification has a critical role in activating downstream molecular targets and leading to a poor prognosis in patients with pNTs (Valentijn et al; 2012; Suganuma et al, 2013). The significance of MYCN overexpression in some neuroblastomas via LIN28B genomic aberrations and overexpression and its signaling pathway involving let-7 miRNAs is also reported (Molenaar et al, 2012).

High-risk neuroblastomas without MYCN amplification are also clinically aggressive, suggesting that factors other than augmented MYCN can also influence tumour behaviour. In our previous study, we have reported MYC protein expression as a new marker of poor prognosis in rare patients with undifferentiated neuroblastoma (Wang et al, 2013). In this study, we extended immunohistochemical analysis of MYCN protein and MYC protein expression to a large cohort of both undifferentiated and poorly differentiated neuroblastoma subtypes to investigate their clinical significance. The prognostic impact of these protein expressions and their association with prominent nucleolar formation were analysed along with other prognostic factors. We found that MYC protein expression was among the most significant predictors of poor disease outcome for undifferentiated/poorly differentiated subtypes of pNTs.

\section{MATERIALS AND METHODS}

Patient cohort. During the year 2009, a total of 604 newly diagnosed pNTs, whose tumour samples were obtained before starting chemotherapy/irradiation therapy, were reviewed at the Children's Oncology Group (COG) Neuroblastoma Pathology Reference Laboratory, Children's Hospital Los Angeles, Los Angeles, California, USA. Those tumours included ganglioneuroma, maturing subtype (23 cases); ganglioneuroblastoma, intermixed (37 cases); ganglioneuroblastoma, nodular (33 cases); and neuroblastoma (511 cases). Among the cases in the neuroblastoma category, there were 20 undifferentiated subtype tumours, 438 poorly differentiated subtype tumours, and 53 differentiating subtype tumours. Of those cases in the neuroblastoma category, 357 tumours (undifferentiated subtype 20, poorly differentiated subtype 337) with available unstained slides in the file of Reference Laboratory were included in this study. In order to avoid a potential confusion in identifying/detecting unique prominent nucleoli, the cases of differentiating subtype were excluded from the study, as differentiating neuroblasts of this subtype had one prominent nucleolus as a sign of nuclear maturation by definition (Shimada et al, 1999a). Nineteen of the 20 tumours of undifferentiated subtype had been included in our previous report
(Wang et al, 2013). Clinical information (age at diagnosis $<18$ months $v s>18$ months; and clinical staging - Stage $4 v s$ nonStage 4 according to the International Neuroblastoma Staging System (INSS)), MYCN status (non-amplified $v s$ amplified), and survival data were collected through the COG study. Informed consent approved by the institutional review board was obtained for all patients at the time of enrollment in the COG biological and/or therapeutic study.

Pathology review. H\&E slides from those 357 cases were reevaluated by LLW, RS, and HS, according to the International Neuroblastoma Pathology Classification (INPC) (Shimada et al, 1999b). Median number of the slides reviewed in this study was 2.0 (ranging 1-32) per case. Diagnostic criteria of undifferentiated and poorly differentiated neuroblastomas are previously described (Shimada et al, 1999a; Wang et al, 2013). MKI class (low MKI; L-MKI $<100$ out of 5000 cells; intermediate MKI; I-MKI 100-200 out of 5000 cells; high MKI; H-MKI > 200 out of 5000 cells) was assigned to the individual tumour as well. Each case was classified into favourable histology or unfavourable histology according to the INPC system (Shimada et al, 1999a,b). Definition of prominent nucleoli was described in our previous report (Suganuma et al, 2013). In the prominent nucleoli $(+)$ tumours, $\geqslant 10 \%$ of the neuroblastic cells had one or a few large prominent nucleoli. In prominent nucleoli $(-)$ tumours, a majority of neuroblastic cells had a conventional salt-and-pepper type nucleus (none or $<10 \%$ of the neuroblastic cells with prominent nucleoli).

Immunohistochemistry. Immunostaining for MYCN and MYC protein was performed using formalin-fixed, paraffin-embedded sections with Leica BOND-MAXTM (Leica Microsystems Inc., Bannockburn, IL, USA) heating for $30 \mathrm{~min}$ in BondTM Epitope Retrieval Solution 2 (No. AR9640; Leica Biosystems Newcastle Ltd., Benton Ln, Newcastle Upon Tyne, UK). The sections were incubated with either anti-MYCN mouse monoclonal antibody, NCM II 100 (Ikegaki et al, 1986) at a dilution of $1: 200$, or antihuman MYC rabbit monoclonal antibody, clone Y69 (No. 1472-1; Epitomics, Cambridge, MA, USA) (Kluk et al, 2012) at a dilution of 1:200 in Bond TM Primary Antibody Diluent (No. AR9352; Vision BioSystems Inc., Norwell, MA, USA). Staining was visualised using Bond Polymer Refine DetectionTM (No. DS9800; Leica Microsystems Inc., Bannockburn, IL, USA). The slides stained for MYC protein were counterstained with hematoxylin. No counterstaining was performed for the slides after MYCN protein staining. The slides were reviewed by HS, LLW, and RT, and results were graded as follows: negative ( - ); focal or sporadic, and weak nuclear staining $( \pm)$; and diffuse and strong nuclear staining with typically heterogeneous intensity $(+)$. Appropriate positive and negative controls were stained along with those tumours.

Statistical analysis. Prognostic effects by MYCN protein expression, MYC protein expression, and other prognostic factors (INSS, MYCN status, INPC, MKI, and prominent nucleoli) were explored for the patients in this series. The association of MYCN and MYC protein expression with each other and with the prognostic factors was examined via a chi-squared test (or Fisher's exact test if small cell sample size). In addition, differences in outcome between specific combinations of MYCN protein, MYC protein, and INPC were investigated. For event-free survival (EFS), time to event was defined as the time from diagnosis until the first event. For overall survival (OS), death was the only event considered. In the absence of an event or death, the survival time was censored at the time of last contact. Survival analyses were performed using the methods of Kaplan and Meier (1958) with s.es. per the methods of Peto et al (1977). Survival curves were compared using a log-rank test. Although no formal adjustments were made for multiple comparisons, $P$-values $<0.05$ were considered statistically significant. 
To determine the independent prognostic strength for survival of the MYCN and MYC protein expression in the presence of the prognostic factors, Cox proportional hazards models with the Efron method of handling tied event times were fit. Age was excluded from the models as INPC is computed using age. Backward selection was used to determine the most parsimonious model.

\section{RESULTS}

MYCN protein and MYC protein expression. Results of the immunostaining are summarised in Figure 1. In this series, 67 tumours showed MYCN protein $(+)$ only, 37 showed MYC protein $(+)$ only, only one had both proteins $(+)$, and 222 were negative for both. Ten tumours were MYCN protein $( \pm)$, including one with MYC protein $( \pm)$ and another one with MYC protein $(+)$. Twenty tumours were MYC protein $( \pm)$ and MYCN protein $(-)$.

As shown in Table 1, 3-year EFS and OS rates of all 357 patients in this study were $69.8 \pm 5.7 \%$ and $83.5 \pm 4.5 \%$, respectively. Table 1 also shows the prognostic impact of MYCN protein expression, MYC protein expression, and the prognostic factors. As the patients with MYCN protein $(-)$ tumour and those with MYCN protein( \pm ) tumour had similar 3-year EFS and 3-year OS rate, they were grouped together for subsequent analyses. Patients with MYCN protein $(-) /( \pm)$ tumour had a significantly better 3year EFS $(75.3 \pm 6.2 \%)$ and 3-year OS $(88.0 \pm 4.5 \%)$ than patients with MYCN protein $(+)$ tumour $(47.4 \pm 11.5 \% 3$-year EFS and $63.8 \pm 11.6 \% 3$-year OS $)(P<0.0001)$. Likewise, patients with MYC protein $(-)$ tumour and those with MYC protein $( \pm)$ tumour had similar 3-year EFS and 3-year OS, and they were grouped together. Patients with MYC protein $(-) /( \pm)$ tumour had a significantly better 3-year EFS $(73.0 \pm 5.8 \%)$ and 3-year OS $(86.1 \pm 4.5 \%)$ than patients with MYC protein $(+)$ tumour $(46.5 \pm 19.6 \% 3$-year EFS and $65.3 \pm 17.2 \%$ 3-year OS $)(P=0.0028 \quad \& \quad P=0.0277$, respectively).

Association between MYCN protein/MYC protein expression and other prognostic markers. Table 1 also confirmed significant prognostic effects by age at diagnosis (median age of the patients at diagnosis in this study was 14.0 months, ranging from 0 to 244 months), INSS, MYCN status (354 cases with available data), INPC, MKI (343 cases with available data), and prominent nucleoli in this series of cases. As shown in Table 2, MYCN protein $(+)$ tumours were almost exclusively MYC protein $(-) /( \pm)$ (67 out of 68) and associated with MYCN amplification (66 out of 67). They were always unfavourable histology (68 out of 68) and more likely to have a high MKI (53 out of 65). MYC protein $(+)$ tumours were almost exclusively MYCN protein $(-) /( \pm$ ) (38 out of 39 ) and non-amplified MYCN (38 out of 39). They were often unfavourable histology (30 out of 39 ) and tended to have a low or intermediate MKI (31 out of 38). Both MYCN protein $(+)$ tumours and MYC protein $(+)$ tumours were often diagnosed in older children ( $>18$ months) with Stage 4 disease compared with MYCN protein $(-) /( \pm)$ tumours and MYC protein $(-) /( \pm)$ tumours, respectively. There was a statistically significant association between prominent nucleolar formation and $\mathrm{MYCN}$ protein or MYC protein expression (Figure 2). The majority (95 out of 110, $86.4 \%$ ) of prominent nucleoli $(+)$ tumours expressed MYCN protein $(+)$ only $(66$ cases, $60.0 \%)$, MYC protein $(+)$ only $(28$ cases, $25.5 \%)$, or both proteins $(+)$ ( 1 case, $0.9 \%)$. In contrast, 236 of the $247(95.5 \%)$ prominent nucleoli ( - ) tumours were $\operatorname{MYCN}(-)$ or $( \pm)$ and $\operatorname{MYC}(-)$ or $( \pm)$.

Association between MYCN protein/MYC protein expression and INPC. Further analysis of prognostic impact by MYCN and MYC protein expression was performed using a total of 355 cases ( 2 cases: 1 tumour with both $\mathrm{MYCN}(+)$ and $\operatorname{MYC}(+)$ and 1 tumour with $\operatorname{MYCN}( \pm)$ and $\operatorname{MYC}(+)$, were excluded from the analysis), and they were divided into four subtypes by combination of protein expression and INPC; that is, 'MYCN protein $(+)$ only, 67 cases, all unfavourable histology $(46.2 \pm 12.0 \%$ 3-year EFS, $63.2 \pm 12.1 \%$ 3-year OS)', 'MYC protein $(+)$ only, 37 cases including 29 unfavourable histology $(43.4 \pm 23.1 \%$ 3-year EFS, $63.5 \pm 19.2 \%$ 3-year OS)', 'favourable histology and MYCN protein $(-) /( \pm)$ and MYC protein $(-) /( \pm), 167$ cases $(89.7 \pm 5.5 \%$ 3-year EFS, $97.0 \pm 3.2 \%$ 3-year OS)', and 'unfavourable histology and MYCN protein $(-) /( \pm)$ and MYC protein $(-) /( \pm), 84$ cases $(63.1 \pm 13.6 \%$ 3-year EFS, $83.5 \pm 9.4 \% 3$-year OS)'. As shown in Figure 3, patients with favourable histology without MYCN protein $(+)$ and MYC protein $(+)$ fared the best in EFS and OS. Patients with MYCN protein $(+)$ only and those with MYC protein $(+)$ only had similar survival rates with the former having the worst OS and the latter having the worst EFS.

\section{Multivariate analysis}

Testing the independent prognostic strength for survival of MYCN protein(+) expression. A full backward-selected Cox model in terms of EFS indicated that INSS and INPC were predictive of survival, with Stage 4 and unfavourable histology

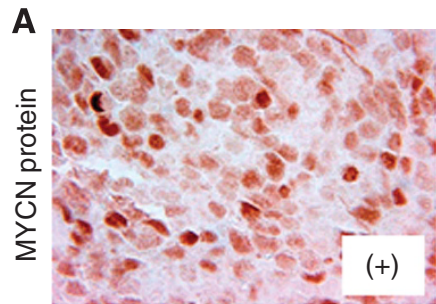

B

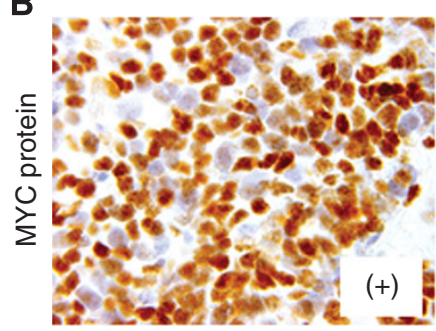

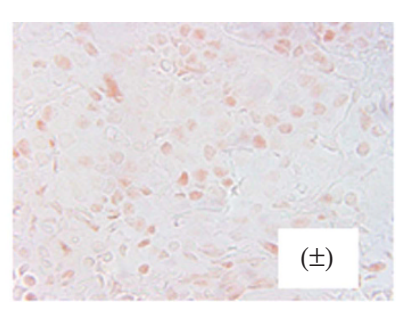

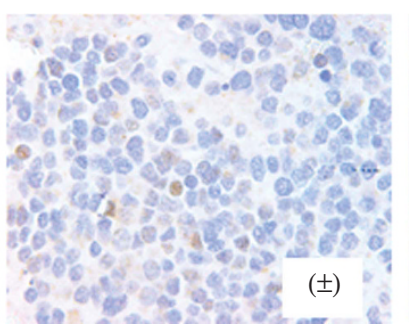

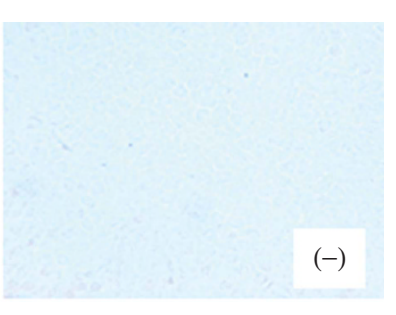

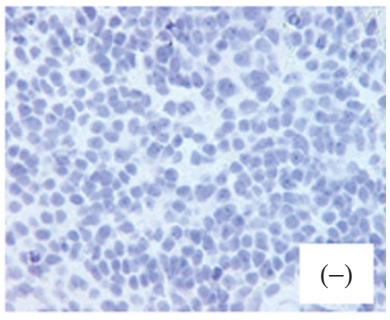

Figure 1. MYCN and MYC protein expression in neuroblastoma. Immunostaining for (A) MYCN protein and (B) MYC protein. Results are graded as $(+),( \pm)$ and $(-)$. Please see 'Materials and Methods - Immunohistochemistry' for grading method. Immunostaining, original magnification $\times 400$. 
Table 1. Summary of survival rates and log-rank test comparisons by prognostic factors

\begin{tabular}{|c|c|c|c|c|c|}
\hline Cohort & $n$ & 3-year EFS \pm s.e. (\%) & EFS $P$-value & 3-year OS \pm s.e. (\%) & OS $P$-value \\
\hline Overall & 357 & $69.8 \pm 5.7$ & NA & $83.5 \pm 4.5$ & NA \\
\hline MYCN protein & & & 0.0003 & & $<0.0001$ \\
\hline $\begin{array}{l}(-) \\
( \pm) \\
(+)\end{array}$ & $\begin{array}{r}279 \\
10 \\
68\end{array}$ & $\begin{array}{l}75.2 \pm 6.2 \\
77.8 \pm 36.7 \\
47.4 \pm 11.5\end{array}$ & & $\begin{array}{l}87.9 \pm 4.7 \\
88.9 \pm 21.0 \\
63.8 \pm 11.6\end{array}$ & \\
\hline MYCN protein & & & $<0.0001$ & & $<0.0001$ \\
\hline $\begin{array}{l}(-) /( \pm) \\
(+)\end{array}$ & $\begin{array}{r}289 \\
68\end{array}$ & $\begin{array}{l}75.3 \pm 6.2 \\
47.4 \pm 11.5\end{array}$ & & $\begin{array}{l}88.0 \pm 4.5 \\
63.8 \pm 11.6\end{array}$ & \\
\hline MYC protein & & & 0.0157 & & 0.0841 \\
\hline $\begin{array}{l}(-) \\
( \pm) \\
(+)\end{array}$ & $\begin{array}{r}297 \\
21 \\
39\end{array}$ & $\begin{array}{l}72.5 \pm 5.9 \\
81.0 \pm 25.0 \\
46.5 \pm 19.6\end{array}$ & & $\begin{array}{l}85.9 \pm 4.6 \\
90.5 \pm 19.7 \\
65.3 \pm 17.2\end{array}$ & \\
\hline MYC protein & & & 0.0028 & & 0.0277 \\
\hline $\begin{array}{l}(-) /( \pm) \\
(+)\end{array}$ & $\begin{array}{r}318 \\
39\end{array}$ & $\begin{array}{l}73.0 \pm 5.8 \\
46.5 \pm 19.6\end{array}$ & & $\begin{array}{l}86.1 \pm 4.5 \\
65.3 \pm 17.2\end{array}$ & \\
\hline Age at diagnosis & & & 0.0003 & & 0.005 \\
\hline $\begin{array}{l}<18 \text { months } \\
\geqslant 18 \text { months }\end{array}$ & $\begin{array}{l}210 \\
147\end{array}$ & $\begin{array}{l}82.5 \pm 6.0 \\
53.1 \pm 10.1\end{array}$ & & $\begin{array}{l}88.5 \pm 5.1 \\
76.6 \pm 7.9\end{array}$ & \\
\hline INSS Stage & & & $<0.0001$ & & $<0.0001$ \\
\hline $\begin{array}{l}1,2,3,4 s \\
4\end{array}$ & $\begin{array}{l}196 \\
161\end{array}$ & $\begin{array}{l}88.1 \pm 5.4 \\
48.3 \pm 9.3\end{array}$ & & $\begin{array}{l}95.0 \pm 3.7 \\
70.0 \pm 8.0\end{array}$ & \\
\hline MYCN status & & & $<0.0001$ & & $<0.0001$ \\
\hline $\begin{array}{l}\text { Not amplified } \\
\text { Amplified }\end{array}$ & $\begin{array}{r}272 \\
82\end{array}$ & $\begin{array}{l}76.5 \pm 6.1 \\
48.1 \pm 11.5\end{array}$ & & $\begin{array}{l}88.5 \pm 4.5 \\
65.8 \pm 11.1\end{array}$ & \\
\hline Histology & & & $<0.0001$ & & $<0.0001$ \\
\hline $\begin{array}{l}\text { Favourable } \\
\text { Unfavourable }\end{array}$ & $\begin{array}{l}176 \\
181\end{array}$ & $\begin{array}{l}87.9 \pm 5.8 \\
53.4 \pm 8.6\end{array}$ & & $\begin{array}{l}95.4 \pm 3.8 \\
72.5 \pm 7.3\end{array}$ & \\
\hline MKI & & & $<0.0001$ & & $<0.0001$ \\
\hline $\begin{array}{l}\text { Low } \\
\text { Intermediate } \\
\text { High }\end{array}$ & $\begin{array}{r}159 \\
103 \\
81\end{array}$ & $\begin{array}{l}83.9 \pm 7.2 \\
65.7 \pm 11.1 \\
55.3 \pm 11.7\end{array}$ & & $\begin{array}{l}94.7 \pm 4.6 \\
80.7 \pm 8.6 \\
63.7 \pm 11.6\end{array}$ & \\
\hline Prominent nucleoli & & & $<0.0001$ & & $<0.0001$ \\
\hline $\begin{array}{l}(-) \\
(+)\end{array}$ & $\begin{array}{l}247 \\
110 \\
\end{array}$ & $\begin{array}{l}78.8 \pm 6.0 \\
50.2 \pm 11.2 \\
\end{array}$ & & $\begin{array}{l}91.6 \pm 4.0 \\
65.7 \pm 10.7\end{array}$ & \\
\hline
\end{tabular}

tumours corresponding to an increase in the risk of event of 3.101 and 2.206, respectively (Please see Supplementary Table). The order of removal was MKI, MYCN status, and MYCN protein expression, with the least statistically significant term dropping out at each step. The last term removed from the model, MYCN protein $(+)$ expression, was dropped with a $P$-value of 0.0619 . A full backward-selected Cox model in terms of OS indicated that INSS and MKI were predictive of survival, with Stage 4 and high MKI tumours corresponding to an increase in the risk of death of 5.194 and 3.220, respectively. The order of removal was MYCN status, MYCN protein $(+)$ expression, and INPC, with the least statistically significant term dropping out at each step. The last term removed from the model, histology, was dropped with a $P$-value of 0.0639 .

Testing the independent prognostic strength for survival of the MYC protein $(+)$ expression. A full backward-selected Cox model in terms of EFS indicated that MYC protein expression, INSS, and MYCN status were predictive of survival, with MYC protein $(+)$, Stage 4, and MYCN-amplified tumours corresponding to an increase in the risk of event of 2.121, 3.656, and 2.077, respectively. The order of removal was MKI and INPC, with the least statistically significant term dropping out at each step. The last term removed from the model, INPC, was dropped with a $P$-value of 0.1079. A full backward-selected Cox model in terms of OS indicated that MYC protein $(+)$ expression, INSS, and MKI were predictive of survival, with MYC protein $(+)$ expression, Stage 4, and high MKI tumours corresponding to an increase in the risk of death of 2.277, 5.066, and 3.619, respectively. The order of removal was INPC and MYCN status, with the least statistically significant term dropping out at each step. The last term removed from the model, MYCN status, was dropped with a $P$-value of 0.1437 .

\section{DISCUSSION}

MYCN amplification with subsequent MYCN protein overexpression is a well-established genomic marker of poor prognosis of the patients with pNTs (Brodeur et al, 1984; Seeger et al, 1985). However, only recently has the prognostic significance of MYC protein expression been recognised, when we reported the impact of MYC protein expression for predicting aggressive tumour behaviour in a small group of patients with undifferentiated neuroblastoma (Wang et al, 2013). The current study is the first in-depth analysis on the prognostic significance of MYCN protein and MYC protein expression in a large cohort of neuroblastoma cases from the COG. This study clearly showed that a significant number of neuroblastomas of undifferentiated/poorly differentiated 
Table 2. Cross-tabulation: MYCN protein expression, MYC protein expressions and prognostic factors

\begin{tabular}{|c|c|c|c|c|c|c|}
\hline & \multicolumn{2}{|c|}{ MYCN protein } & \multirow[b]{2}{*}{$P$-value ${ }^{a}$} & \multicolumn{2}{|c|}{ MYC protein } & \multirow[b]{2}{*}{$P$-value } \\
\hline & $(-) /( \pm)$ & $(+)$ & & $(-) /( \pm)$ & $(+)$ & \\
\hline \multicolumn{7}{|l|}{ MYC protein } \\
\hline $\begin{array}{l}(-) /( \pm) \\
(+)\end{array}$ & $\begin{array}{r}251 \\
38\end{array}$ & $\begin{array}{r}67 \\
1\end{array}$ & $0.0039^{b}$ & & & \\
\hline \multicolumn{7}{|c|}{ Age at diagnosis } \\
\hline $\begin{array}{l}<18 \text { months } \\
\geqslant 18 \text { months }\end{array}$ & $\begin{array}{l}187 \\
102\end{array}$ & $\begin{array}{l}23 \\
45\end{array}$ & $<0.0001$ & $\begin{array}{l}199 \\
119\end{array}$ & $\begin{array}{l}11 \\
28\end{array}$ & $<0.0001$ \\
\hline \multicolumn{7}{|l|}{ INSS stage } \\
\hline $\begin{array}{l}1,2,3,4 s \\
4\end{array}$ & $\begin{array}{l}173 \\
116\end{array}$ & $\begin{array}{l}23 \\
45\end{array}$ & 0.0001 & $\begin{array}{l}182 \\
136\end{array}$ & $\begin{array}{l}14 \\
25\end{array}$ & 0.0115 \\
\hline \multicolumn{7}{|c|}{ MYCN status } \\
\hline $\begin{array}{l}\text { Not amplified } \\
\text { Amplified }\end{array}$ & $\begin{array}{r}271 \\
16\end{array}$ & $\begin{array}{r}1 \\
66\end{array}$ & $<0.0001^{b}$ & $\begin{array}{r}234 \\
81\end{array}$ & $\begin{array}{r}38 \\
1\end{array}$ & $0.0004^{k}$ \\
\hline \multicolumn{7}{|l|}{ Histology } \\
\hline $\begin{array}{l}\text { Favourable } \\
\text { Unfavourable }\end{array}$ & $\begin{array}{l}176 \\
113\end{array}$ & $\begin{array}{r}0 \\
68\end{array}$ & $<0.0001^{b}$ & $\begin{array}{l}167 \\
151\end{array}$ & $\begin{array}{r}9 \\
30\end{array}$ & 0.0005 \\
\hline \multicolumn{7}{|l|}{ MKI } \\
\hline $\begin{array}{l}\text { Low } \\
\text { Intermediate } \\
\text { High }\end{array}$ & $\begin{array}{r}156 \\
94 \\
28\end{array}$ & $\begin{array}{r}3 \\
9 \\
53\end{array}$ & $<0.0001^{b}$ & $\begin{array}{r}149 \\
82 \\
74\end{array}$ & $\begin{array}{r}10 \\
21 \\
7\end{array}$ & 0.0013 \\
\hline
\end{tabular}

A

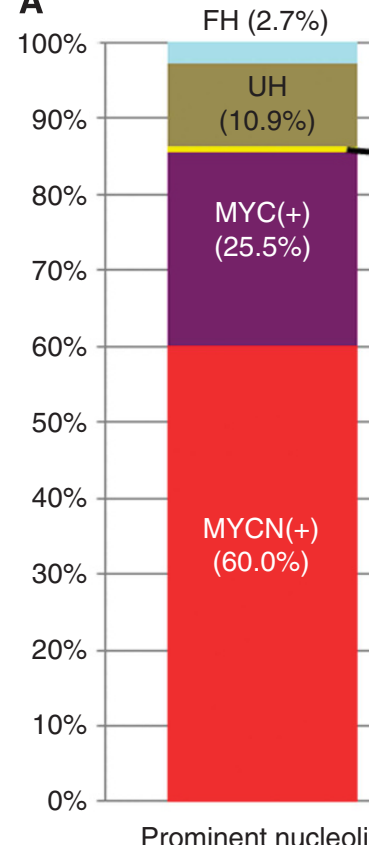

(+) $N=110$

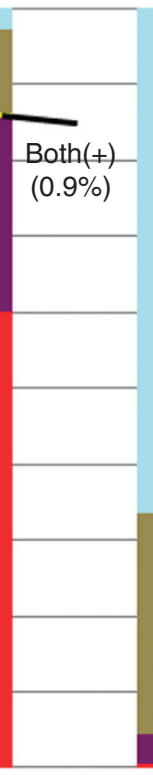

Promin

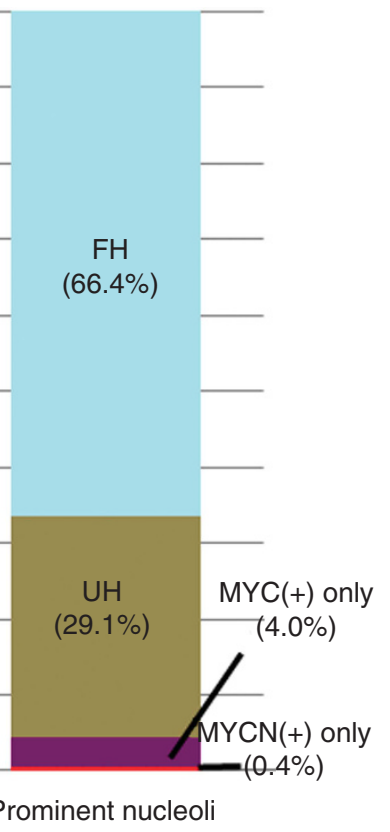

(-) $N=247$
B
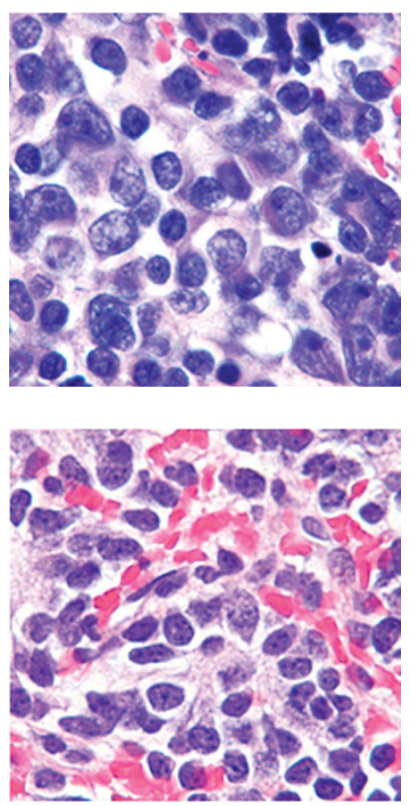

Figure 2. Prominent nucleolar formation in 357 neuroblastomas of undifferentiated/poorly differentiated subtypes. (A) Bar graph shows case distribution by prominent nucleolar formation. Left: Tumours with prominent nucleolar formation, Right: Tumours without prominent nucleolar formation. $\mathrm{MYCN}(+)=\mathrm{MYCN}$ protein( + ) tumours (red); $\mathrm{MYC}(+)=\mathrm{MYC}$ protein $(+)$ tumours (purple); Both $(+)=$ one tumour with both $\mathrm{MYCN}$ protein $(+)$ and MYC protein( + ) (yellow); UH = unfavourable histology tumours with MYCN protein $(-)$ or $( \pm)$ and MYC protein( - ) or ( \pm ) (brown); $\mathrm{FH}=$ favourable histology tumours with MYCN protein $(-)$ or $( \pm)$ and MYC protein $(-)$ or $( \pm)$ (light blue). Tumours having prominent nucleoli are predominantly composed of MYCN protein $(+)$ or MYC protein $(+)$ neuroblastomas. (B) Panel shows histology of neuroblastoma with prominent nucleolar formation (upper) and without prominent nucleolar formation (lower). H\&E staining, original magnification $\times 1000$.

subtypes expressed either MYCN protein $((+)$ detected immunohistochemically in $19.0 \%$ of the tumours) or MYC protein $((+)$ detected in $10.9 \%$ of the tumours). As both of MYC and MYCN oncogenes are members of the MYC family gene, we classified those tumours expressing high levels of either MYCN protein or MYC protein as MYC-driven neuroblastomas. Results of this study are consistent with the work by Fredlund et al (2008) reporting that activation of the Myc transcriptional network is 
A

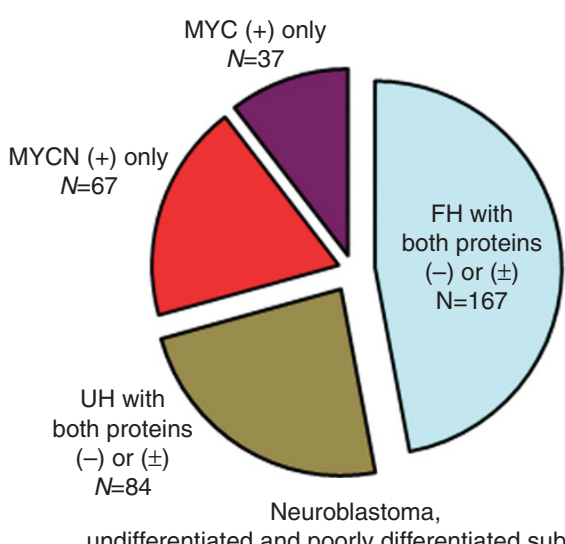

undifferentiated and poorly differentiated subtypes $(N=355)$
B

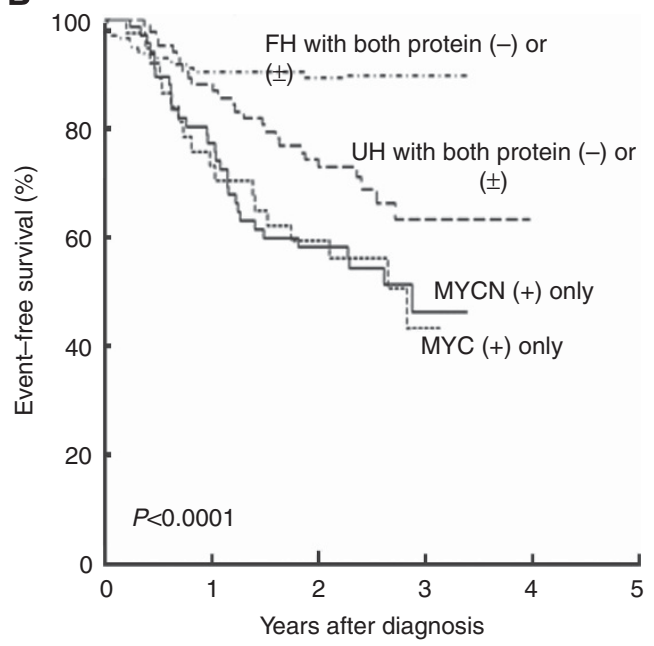

Figure 3. Case distribution and survival by protein expression and International Neuroblastoma Pathology Classification. (A) Distribution of 355 neuroblastomas of undifferentiated/poorly differentiated subtypes (two cases; one with MYCN $(+) / \mathrm{MYC}(+)$ and one with $\mathrm{MYCN}( \pm) / \mathrm{MYC}(+)$, were excluded from the analysis). (B) Event-free survivals for the four groups. Patients with MYCN protein $(+)$ tumour had a similar and significantly low survival rate compared with those with MYC protein(+) tumour. Abbreviations: $F H=$ favourable histology; $M Y C=M Y C$ protein; $\mathrm{MYCN}=\mathrm{MYCN}$ protein; $\mathrm{UH}=$ unfavourable histology.

associated with poor outcome in neuroblastoma patients. In fact, our study suggests that elevated MYC and MYCN protein expression lays foundation for the Myc transcriptional network activation in neuroblastoma.

Clinically, both MYCN protein(+) and MYC protein $(+)$ tumours were more likely diagnosed in older children $(>18$ months at diagnosis) and with Stage 4 disease. All of the MYCN protein $(+)$ tumours and the majority of the MYC protein $(+)$ tumours were classified as unfavourable histology according to the INPC. Most importantly, those MYC-driven tumours, with either MYCN protein $(+)$ or MYC protein $(+)$ expression, were significantly associated with a poor clinical outcome and had similar EFS and OS rates. When compared with other prognostic factors, in addition to INSS and MYCN status or MKI, MYC protein $(+)$ expression maintained independent statistical significance for prediction of clinical outcome.

In order to function as a transcriptional factor, both MYCN and MYC genes need to be transcribed and translated into MYCN protein and MYC protein production. This study showed that MYCN protein $(+)$ expression was almost exclusively associated with MYCN amplification, while MYC protein $(+)$ expression was almost exclusively found without MYCN amplification. It is known, from the cell line experiments (Breit and Schwab, 1989), that these two proteins inhibit the expression of the other protein in each other, so that simultaneous expression of both MYCN protein and MYC protein in the same tumours is expected to be rare: only one case had $(+)$ for both proteins in our series. Though the systemic analysis of MYC status was not conducted in this study, it was noted that those MYC protein $(+)$ tumours were not necessarily associated with $M Y C$ gene amplification. We experienced only one neuroblastoma case with proven $M Y C$ amplification and MYC protein overexpression in our recent file, and the case was not included in this study. Apparently, MYC amplification leading to augmented MYC protein expression is a very rare event in neuroblastoma (Saito-Ohara et al, 2003; Valentijn et al, 2012).

Both MYCN protein and MYC protein are known to make a complex with MAX (MYC-associated factor X) protein. MYCMAX heterodimer activates pathways involved in cell proliferation, inhibition of differentiation, apoptosis, and so on (Dang, 1999; Baudino and Cleveland, 2001; Adhikary and Eilers, 2005; Meyer and Penn, 2008; Huang et al, 2011). Functional similarity and complementarity between MYCN protein and MYC protein have been confirmed by experiments using transgenic mice (Malynn et al, 2000). Both proteins are essential for embryonal development, and MYCN- or MYC-deficient mice are lethal. In addition, mice in which the MYC gene is replaced with the MYCN gene can survive until adulthood, suggesting their functional redundancy. It is interesting to note, however, that MYCN protein $(+)$ tumours frequently had a high MKI, while MYC protein $(+)$ tumours were more likely to have a low or intermediate MKI, and the major quantitative difference in MKI in these tumours was due to the difference in karyorrhexis rather than in mitosis (data not shown). The difference in karyorrhectic activities in MYCN protein $(+)$ and MYC protein $(+)$ tumours suggests that these two proteins could have some functional difference especially in their apoptotic/karyorrhectic pathways. It is also speculated that the cellular and/or developmental origin of these tumour cells could be different in terms of their epigenetic landscape where MYC family protein interact to show their biological effect. In chick embryo, for example, it is documented that the expression patterns of MYCN protein and MYC protein are different in different stages of the neural crest development (Khudyakov and Bronner-Fraser, 2009).

Our results also showed that prominent nucleolar formation correlated strongly with MYCN protein $(+)$ or MYC protein $(+)$ overexpression in neuroblastoma of undifferentiated and poorly differentiated subtypes. Prominent nucleoli were detected in 66 out of $67 \mathrm{MYCN}$ protein $(+)$ tumours, 28 out of $38 \mathrm{MYC}$ protein $(+)$ tumours, and 1 out of 1 tumour with both proteins $(+)$. The nucleolus is the location where ribosome synthesis takes place, and the association between nucleoli hypertrophy and poorer prognosis has been reported in various human cancers, including neuroblastoma (Tornóczky et al, 2004; Derenzini, Montanaro and Treré, 2009; Suganuma et al, 2013). It should also be mentioned that prominent nucleolar formation was often associated with a unique and vesicular nuclear morphology, indicative of increased euchromatin content. Undifferentiated/poorly differentiated neuroblastomas composed of tumour cells having a vesicular nucleus with a few prominent nucleoli were previously described as 'largecell' neuroblastomas (LCNs) (Tornóczky et al, 2004). Recently, we also revealed a biologically remarkable similarity between LCNs and xenograft tumours derived from stem cell-like neuroblastoma cells, which were created by transient exposure of conventional NB cell lines with epigenetic modifiers (Ikegaki et al, 2013). These stem 
cell-like neuroblastoma cells, termed neuroblastoma iCSCs (induced cancer stem cells), express high levels of MYC or MYCN as well as a number of neural stem-cell markers.

In summary, about $30 \%$ of neuroblastoma cases in the undifferentiated and poorly differentiated subtypes were MYCdriven, expressing either MYCN protein or MYC protein in this series of cases. Notably, this subset would comprise of the highestrisk neuroblastoma cases. With the results of this report, we should move on to a prospective study of MYC and MYCN protein expression as a new biomarker for high-risk neuroblastomas.

\section{ACKNOWLEDGEMENTS}

This work was in part supported by NIH grants: U10CA98413, U10CA98543, PO1CA081403, and R01CA127571.

\section{REFERENCES}

Adhikary S, Eilers M (2005) Transcriptional regulation and transformation by Myc proteins. Nat Rev Mol Cell Biol 6: 635-645.

Baudino TA, Cleveland JL (2001) The Max network gone mad. Mol Cell Biol 21: 691-702.

Breit S, Schwab MJ (1989) Suppression of MYC by high expression of NMYC in human neuroblastoma cells. J Neurosci Res 24: 21-28.

Brodeur GM, Seeger RC, Schwab M, Varmus HE, Bishop JM (1984) Amplification of $\mathrm{N}$-myc in untreated human neuroblastoma correlates with advanced disease stage. Science 224: 1121-1124.

Brodeur GM, Pritchard J, Berthold F, Carlsen NL, Castel V, Castelberry RP, De Bernardi B, Evans AE, Favrot M, Hedborg F (1993) Revisions of the international criteria for neuroblastoma diagnosis, staging, and response to treatment. J Clin Oncol 11: 1466-1477.

Cohn SL, Pearson AD, London WB, Monclair T, Ambros PF, Brodeur GM, Faldum A, Hero B, Iehara T, Machin D, Mosseri V, Simon T, Garaventa A, Castel V, Matthay KK (2009) The International Neuroblastoma Risk Group (INRG) classification system: an INRG task force report. J Clin Oncol 27: 289-297.

Dang CV (1999) c-Myc target genes involved in cell growth, apoptosis, and metabolism. Mol Cell Biol 19: 1-11.

Derenzini M, Montanaro L, Treré D (2009) What the nucleolus says to a tumour pathologist. Histopathology 54: 753-762.

Fredlund E, Ringnér M, Maris JM, Påhlman S (2008) High Myc pathway activity and low stage of neuronal differentiation associate with poor outcome in neuroblastoma. Proc Natl Acad Sci USA 105: 14094-14099.

Goto S, Umehara S, Gerbing RB, Stram DO, Brodeur GM, Seeger RC, Lukens JN, Matthay KK, Shimada H (2001) Histopathology (International Neuroblastoma Pathology Classification) and MYCN status in patients with peripheral neuroblastic tumors: a report from the Children's Cancer Group. Cancer 92: 2699-2708.

Huang R, Cheung NK, Vider J, Cheung IY, Gerald WL, Tickoo SK, Holland EC, Blasberg RG (2011) MYCN and MYC regulate tumor proliferation and tumorigenesis directly through BMIlin Human neuroblastoma. FASEB J 25: 4138-4149.

Ikegaki N, Bukovsky J, Kennett RH (1986) Identification and characterization of the NMYC gene product in human neuroblastoma cells by monoclonal antibodies with defined specificities. Proc Natl Acad Sci USA 83: 5929-5933.

Ikegaki N, Shimada H, Fox AM, Regan PL, Jacobs JR, Hicks SL, Rappaport EF, Tang XX (2013) Transient treatment with epigenetic modifiers yields stable neuroblastoma stem cells resembling aggressive large-cell neuroblastomas. Proc Natl Acad Sci USA 110: 6097-6102.

Kaplan EL, Meier P (1958) Non-parametric estimation from incomplete observations. J Am Stat Assoc 53: 457-481.

Khudyakov J, Bronner-Fraser M (2009) Comprehensive spatiotemporal analysis of early chick neural crest network genes. Dev Dyn 238: 716-723.

Kluk MJ, Chapuy B, Sinha P, Roy A, Dal Cin P, Neuberg DS, Monti S, Pinkus GS, Shipp MA, Rodig SJ (2012) Immunohistochemical detection of MYC-driven diffuse large B-cell lymphomas. PLoS One 7: e33813.
Kobayashi C, Monforte-Munoz HL, Gerbing RB, Stram DO, Matthay KK, Lukens JN, Seeger RC, Shimada H (2005) Enlarged and prominent nucleoli may be indicative of MYCN amplification. Cancer 103: 174-180.

Malynn BA, de Alboran IM, O'Hagan RC, Bronson R, Davidson L, DePinho RA, Alt FW (2000) N-myc can functionally replace c-myc in murine development, cellular growth, and differentiation. Genes Dev 14: 1390-1399.

Maris JM, Hogarty MD, Bagatell R, Cohn SL (2007) Neuroblastoma. Lancet 369: $2106-2120$.

Meyer N, Penn LZ (2008) Reflecting on 25 years with MYC. Nat Rev Cancer 8 : 976-990.

Molenaar JJ, Domingo-Fernández R, Ebus ME, Lindner S, Koster J, Drabek K, Mestdagh P, van Sluis P, Valentijn LJ, van Nes J, Broekmans M, Haneveld F, Volckmann R, Bray I, Heukamp L, Sprüssel A, Thor T, Kieckbusch K, Klein-Hitpass L, Fischer M, Vandesompele J, Schramm A, van Noesel MM, Varesio L, Speleman F, Eggert A, Stallings RL, Caron HN, Versteeg R, Schulte JH (2012) LIN28B induces neuroblastoma and enhances MYCN levels via let-7 suppression. Nat Genet 44: 1199-1206.

Peto R, Pike MC, Armitage P, Breslow NE, Cox DR, Howard SV, Mantel N, McPherson K, Peto J, Smith PG (1977) Design and analysis of randomized clinical trials requiring prolonged observation of each patient. Part II: Analysis and examples. Br J Cancer 35: 1-39.

Saito-Ohara F, Imoto I, Inoue J, Hosoi H, Nakagawara A, Sugimoto T, Inazawa J (2003) PPM1D is a potential target for 17q gain in neuroblastoma. Cancer Res. 63: 1876-1883.

Seeger RC, Brodeur GM, Sather H, Dalton A, Siegel SE, Wong KY, Hammond D (1985) Association of multiple copies of the N-myc oncogene with rapid progression of neuroblastomas. N Engl J Med 313: 1111-1116.

Shimada H, Ambros IM, Dehner LP, Hata J, Joshi VV, Roald B (1999a) Terminology and morphologic criteria of neuroblastic tumors: recommendations by the International Neuroblastoma Pathology Committee. Cancer 86: 349-363.

Shimada H, Ambros IM, Dehner LP, Hata J, Joshi VV, Roald B, Stram DO, Gerbing RB, Lukens JN, Matthay KK, Castleberry RP (1999b) The International Neuroblastoma Pathology Classification (the Shimada System). Cancer 86: 364-372.

Suganuma R, Wang LL, Sano H, Naranjo A, London WB, Seeger RC, Hogarty MD, Gastier-Foster JM, Look AT, Park JR, Maris JM, Cohn SL, Amann G, Beiske K, Cullinane CJ, d'Amore ES, Gambini C, Jarzembowski JA, Joshi VV, Navarro S, Peuchmaur M, Shimada H (2013) Peripheral neuroblastic tumors with genotype phenotype discordance: A report from the Children's Oncology Group and the International Neuroblastoma Pathology Committee. Pediatr Blood Cancer 60: 363-370.

Thorner PS, Ho M, Chilton-MacNeill S, Zielenska M (2006) Use of chromogenic in situ hybridization to identify MYCN gene copy number in neuroblastoma using routine tissue sections. Am J Surg Pathol 30: 635-642.

Tornóczky T, Kálmán E, Kajtár PG, Nyári T, Pearson AD, Tweddle DA, Board J, Shimada H (2004) Large cell neuroblastoma: a distinct phenotype of neuroblastoma with aggressive clinical behavior. Cancer 100: 390-397.

Valentijn LJ, Koster J, Haneveld F, Aissa RA, van Sluis P, Broekmans ME, Molenaar JJ, van Nes J, Versteeg R (2012) Functional MYCN signature predicts outcome of neuroblastoma irrespective of MYCN amplification. Proc Natl Acad Sci USA 109: 19190-19195.

Wang LL, Suganuma R, Ikegaki N, Tang X, Naranjo A, McGrady P, London WB, Hogarty MD, Gastier-Foster JM, Look AT, Park JR, Maris JM, Cohn SL, Seeger RC, Shimada H (2013) Neuroblastoma of undifferentiated subtype, prognostic significance of prominent nucleolar formation, and MYC/MYCN protein expression: a report from the Children's Oncology Group. Cancer 119: 3718-3726.

Weinstein JL, Katzenstein HM, Cohn SL (2003) Advances in the diagnosis and treatment of neuroblastoma. Oncologist 8: 278292.

This work is published under the standard license to publish agreement. After 12 months the work will become freely available and the license terms will switch to a Creative Commons AttributionNonCommercial-Share Alike 4.0 Unported License 